\title{
Zinc, Cobre y Hierro Sérico en Ovejas de Pelo con Suplementación Parenteral de Minerales
}

\author{
Serum Zinc, Iron and Copper in Hair Sheep with Parenteral Supplementation \\ OF Minerals
Arnoldo González-Reyna, Floriberto Naranjo-García, Pedro Zárate-Fortuna†, Jonny Juárez-Félix, Martín Antonio Ibarra-Hinojosa, Andrés Gilberto \\ Limas-Martínez, Juan Carlos Martínez-González ${ }^{1,2}$
}

\section{Resumen}

El objetivo del presente estudio fue evaluar el efecto de tres formulaciones minerales (comerciales) sobre los niveles de zinc $(\mathrm{Zn})$, hierro $(\mathrm{Fe})$ y cobre $(\mathrm{Cu})$ en suero sanguíneo de ovejas de pelo. Se seleccionaron 48 ovejas de las razas Pelibuey Canelo y Katahdin, de $2.5 \pm 0.5$ años de edad, $45.0 \pm 5.0 \mathrm{~kg}$ de peso y de 2.5 a 4.0 de condición corporal. Se utilizó un diseño completamente al azar, con 12 repeticiones y cuatro tratamientos, los cuales consistieron en la aplicación del suplemento mineral vía parenteral: T1 = testigo (Vit $\mathrm{ADE})$; T2 = $993 \mathrm{mg}$ de P + $45 \mathrm{mg}$ de Se + Vit ADE; T3 = $993 \mathrm{mg}$ de P + Vit D3 + Vit ADE; $\mathrm{y}$ $\mathrm{T} 4=670 \mathrm{mg}$ de $\mathrm{Zn}+987 \mathrm{mg}$ de $\mathrm{Mg}+795 \mathrm{mg}$ de Ca + Vit ADE. Las medias de $\mathrm{Zn}, \mathrm{Fe} \mathrm{y} \mathrm{Cu}$ fueron $1.56,3.08$ y $0.53 \mathrm{ppm}$, respectivamente. No se encontraron diferencias significativas entre tratamientos ni en la interacción entre tratamientos x periodos; sin embargo, los periodos afectaron la concentración de minerales en el suero sanguíneo $(p<0.05)$. Se concluye que la suplementación mineral parenteral en ovejas de pelo no afectó de manera significativa la concentración sérica de minerales en ovinos de pelo.

Palabras clave: minerales, suero sanguíneo, ovinos de pelo

\section{AbstraCt}

The objective of this study was to evaluate the effect of three mineral formulations (commercial) on the serum concentration of zinc $(\mathrm{Zn})$, iron $(\mathrm{Fe})$ and copper $(\mathrm{Cu})$ of hair sheep. A total of 48 Pelibuey Canelo and Katahdin sheep, $2.5 \pm 0.5$ years old, $45.0 \pm 5.0 \mathrm{~kg}$ body weight and 2.5 to 4.0 body condition score were selected. A completely randomized

\footnotetext{
${ }^{1}$ Facultad de Ingeniería y Ciencias, Centro Universitario Adolfo López Mateos, Universidad Autónoma de Tamaulipas, Ciudad Victoria, Tamaulipas, México

${ }^{2}$ E-mail:jmartinez@docentes.uat.edu.mx
}

Recibido: 10 de marzo de 2016

Aceptado para publicación: 10 de junio de 2016 
design with 12 repetitions and four treatments was used. Mineral supplements via parenteral were supplemented as follows: $\mathrm{T} 1=($ Vit ADE $)$ control; $\mathrm{T} 2=993 \mathrm{mg} \mathrm{P}+45 \mathrm{mg}$ of Se + Vit ADE; T3 $=993 \mathrm{mg}$ of P + Vit D3 + Vit ADE; and T4 =670 $\mathrm{mg} \mathrm{Zn}+987 \mathrm{mg} \mathrm{Mg}+$ $795 \mathrm{mg}$ of $\mathrm{Ca}+\mathrm{Vit} \mathrm{ADE}$. The mean values of $\mathrm{Zn}, \mathrm{Fe}$, and $\mathrm{Cu}$ were $1.54,3.08$ and $0.53 \mathrm{ppm}$ respectively. No significant differences were found between treatments nor in the interaction treatments x periods; however, periods significantly affected the serum concentration of minerals $(\mathrm{p}<0.05)$. It is concluded that parenteral mineral supplementation in hair sheep do not significantly affect serum concentration of minerals.

Key words: minerals, blood serum, sheep hair

\section{INTRODUCCIÓN}

Los elementos minerales son esenciales para todos los animales ya que intervienen en numerosos procesos metabólicos. Su desbalance se manifiesta como deficiencia o toxicidad (Underwood y Suttle, 2003).

Una de las principales deficiencias en la alimentación del ganado, después de la proteína y energía, es la deficiencia mineral, sobre todo en condiciones de pastoreo (McDowell, 2003), debido a que dependen exclusivamente del contenido mineral de los forrajes para satisfacer sus requerimientos nutricionales (Morales et al., 2007; Domínguez-Vara y Huerta-Bravo, 2008; Turriza-Chan et al., 2010).

Los minerales se dividen en macrominerales: calcio $(\mathrm{Ca})$, fósforo $(\mathrm{P})$, sodio $(\mathrm{Na})$, potasio $(\mathrm{K})$, magnesio $(\mathrm{Mg})$, azufre $(\mathrm{S})$ y cloro $(\mathrm{Cl})$; y microminerales: hierro $(\mathrm{Fe})$, cobre $(\mathrm{Cu})$, cobalto $(\mathrm{Co})$, zinc $(\mathrm{Zn})$, manganeso (Mn), yodo (I) y selenio (Se), siendo estos de gran importancia para el organismo animal (McDowell, 2003; Huerta, 2008).

Estudios realizados en $\mathrm{Zn}$ (Miller et al., 1993; Álvarez-Rodríguez et al., 2001) indican su importancia en la división y formación de células somáticas y germinales; asimismo, se le asocia con la síntesis del ADN y ARN. La deficiencia de este mineral en el animal provoca retardo en el crecimiento, anorexia, inflamación de los cascos, alope- cia, hipogonadismo en el macho y aborto en el último tercio de la gestación (Underwood y Suttle, 2003; Church et al., 2007). Los requerimientos de $\mathrm{Zn}$ en ovejas están entre 10 y $33 \mathrm{ppm}$ para un buen funcionamiento fisiológico, crecimiento y producción de lana (Arelovich et al., 2014).

Independientemente del estado de los animales (empadre, gestación, lactancia, etc.) y disponibilidad de los minerales, se observa la conveniencia de suplementar vía parenteral los minerales para corregir las necesidades nutritivas del rumiante (Fraker et al., 2000; Arelovich et al., 2014).

Por otro lado, el cobre $(\mathrm{Cu})$ es un elemento mineral esencial en pequeñas cantidades para la nutrición animal. Es importante para el funcionamiento del sistema nervioso, la pigmentación de la piel, el pelo y la lana, así como en reacciones bioquímicas en el metabolismo enzimático (NRC, 2007). En el caso de las ovejas, su requisito está influenciado por los niveles dietarios de azufre (S) y molibdeno (Mo). De igual modo, el hierro (Fe) es otro de los microminerales que se requieren en mínimas cantidades, pero necesarios para la función metabólica (Linch y Stoltzfus, 2003; McDowell, 2003; Huerta, 2008).

En México, la investigación en nutrición mineral de ovinos es escasa y con frecuencia, los microminerales no se consideran en la dieta. Domínguez-Vara y Huerta-Bravo 
Cuadro1. Composición de los suplementos minerales comerciales

\begin{tabular}{cll}
\hline & $\begin{array}{l}\text { Nombre } \\
\text { comercial }\end{array}$ & \multicolumn{1}{c}{$\begin{array}{c}\text { Ingredientes activos } \\
\left(\mathrm{ml}^{-1}\right)^{1}\end{array}$} \\
\hline T1 & $\begin{array}{l}\text { Compol }{ }^{1} \\
\text { Lapisa }\end{array}$ & $\begin{array}{l}\text { Vit A (500 000 UI) } \\
\text { Vit D (75 000 UI) } \\
\text { Vit E (50 UI) }\end{array}$ \\
& & P 9.93 mg \\
T2 & Fose1 ${ }^{\circledR}$ & Se 0.45 mg \\
& Lapisa & Vit D 6 000 UI \\
& & Vit E 25 UI \\
T3 & Vifato ${ }^{\circledR}$ & P 500 mg \\
& Lapisa & Vit D 500 000 UI \\
T4 & Zimacal ${ }^{\circledR}$ & Zn 6.70 mg \\
& Lapisa & Mg 9.87 mg \\
& & Ca 7.95 mg \\
\hline
\end{tabular}

${ }^{1}$ Vit: vitamina; P: fósforo; Se: selenio;

Zn; zinc; Mg: manganeso; Ca: calcio

(2008), encontraron que la presencia de microminerales en la sangre fue afectada por fuentes ambientales como la unidad de producción, la edad del animal y la época del año. El objetivo de la presente investigación fue evaluar el efecto de la administración de minerales, vía parenteral, sobre sus niveles en suero sanguíneo de ovejas.

\section{Materiales y MéTodos}

La investigación se realizó en la Posta Zootécnica «Ing. Herminio García González» de la Facultad de Ingeniería y Ciencias de la Universidad Autónoma de Tamaulipas, a una altitud de $190 \mathrm{msnm}$. La temperatura y precipitación anual es de $23.9^{\circ} \mathrm{C}$ y $704 \mathrm{~mm}$, respectivamente (CNA, 2014).

Se utilizaron 48 ovejas Pelibuey Canelo $(\mathrm{n}=26)$ y Katahdin $(\mathrm{n}=22)$, con $2.5 \pm 0.5$ años de edad media, $45.0 \pm 5.0 \mathrm{~kg}$ de peso promedio y 2.5 a 4.0 de condición corporal (escala de 1 a 5). Se seleccionaron tomando en cuenta su historial reproductivo, con la finalidad de que fueran fértiles y con buena habilidad materna. Se distribuyeron de manera aleatoria en cuatro tratamientos a base de un suplemento mineral parenteral: $\mathrm{T} 1=\mathrm{Compol} \circledast(2$ $\mathrm{ml}$ animal $\left.{ }^{-1}\right)$ como grupo control; T2 $=$ Fosel ${ }^{\circledR}$ $\left(2 \mathrm{ml}_{\text {animal }}{ }^{-1}\right) ; \mathrm{T} 3=$ Vifato ${ }^{\circledR}\left(10 \mathrm{ml}\right.$ animal $\left.{ }^{-1}\right)$ y T4 = Zimacal ${ }^{\circledR}\left(3.5 \mathrm{ml} \mathrm{animal}^{-1}\right)$. La composición química de los suplementos minerales se muestra en el Cuadro 1.

El experimento tuvo una duración equivalente a dos épocas de partos. La aplicación de los suplementos minerales se realizó en tres ocasiones: en el empadre (mayo a junio de 2011), en el último tercio de la gestación (agosto a septiembre de 2011) y en el segundo empadre (noviembre a diciembre de 2011).

Previo al inicio del experimento y cada seis meses hasta el final del estudio, las ovejas fueron dosificadas contra parásitos internos con $0.2 \mathrm{mg}$ de ivermectina $\mathrm{kg}^{-1}$ de PV (Iverfull ${ }^{\circledR}$, Laboratorios Aranda, México), vía subcutánea, así como con administración parenteral subcutánea de Closatel al 12.5\% (Ivertin $\operatorname{Clos}{ }^{\circledR}$, Laboratorio Calier, Uruguay).

Cuadro 2. Composición química del pasto Tifton $68^{1}$

\begin{tabular}{lc}
\hline Nutrimento & $\begin{array}{c}\text { Media } \pm \text { d.e. } \\
(\%)\end{array}$ \\
\hline Materia seca & $94.2 \pm 2.0$ \\
Proteína bruta & $16.6 \pm 3.1$ \\
Fibra detergente & $69.6 \pm 3.4$ \\
neutro & $34.3 \pm 3.8$ \\
Fibra detergente ácido & $0.5 \pm 0.1$ \\
Calcio & $0.3 \pm 0.1$ \\
Fosforo & $2.6 \pm 0.5$ \\
Potasio & $0.3 \pm 0.0$ \\
Magnesio & \\
\hline 1 Laboratorio de Nutrición Animal de la \\
Facultad de Ingeniería y Ciencias de la \\
Universidad Autónoma de Tamaulipas
\end{tabular}


La alimentación de los cuatro grupos experimentales de borregas fue al pastoreo en pradera de zacate bermuda Tifton 68 (Cynodon nlemfuensis), durante las estaciones de primavera, verano y otoño (Cuadro 2), en tanto que la alimentación en la época de invierno se realizó en corral con una dieta balanceada al $7 \%$ de proteína bruta (PB) y 2.4 Mcal de energía metabolizable (EM) a base de cáscara fresca de cítricos, suplemento proteico y agua a libre acceso. La alimentación basal cubría los requerimientos nutricionales de una dieta de mantenimiento y de acuerdo a la etapa fisiológica de las ovejas (empadre; NRC, 2007), aunque no se pudo determinar los niveles de $\mathrm{Cu}$, Fe y $\mathrm{Zn}$ proporcionados por las pasturas ni por la dieta de invierno.

Se colectaron muestras de sangre los días $-5,0,10,25,40,60$ y 90 de la aplicación de los suplementos parenterales. La toma de muestras se realizó a la misma hora del día $(8: 00 \mathrm{am})$ en tubos sin anticoagulante $(7 \mathrm{ml}$, BD Vacutainer ${ }^{\circledR}$, New Jersey, USA), por punción directa de la vena yugular. La sangre fue centrifugada a $559 \mathrm{~g}$ durante $20 \mathrm{~m}$ a $4{ }^{\circ} \mathrm{C}$ y el suero resultante fue congelado a $-20{ }^{\circ} \mathrm{C}$. No fue posible hacer biopsias de hígado para determinar las reservas de algunos de estos minerales en los animales al inicio y al final del experimento.

Se agregó a las muestras de suero, previo al análisis mineral, $2 \mathrm{ml}$ de ácido tricloroacético al 10\% para obtener una solución desprovista de proteínas. Las concentraciones de $\mathrm{Ca}, \mathrm{P}, \mathrm{Mg}$, Se y $\mathrm{Zn}$ en el suero fueron determinadas mediante espectrofotometría de absorción atómica (210 VGP, Buck Scientific ${ }^{\circledR}$, Connecticut, EEUU).

Se utilizó un diseño experimental completamente al azar con cuatro tratamientos. La comparación entre medias, cuando existieron diferencias, se realizó mediante la prueba de Tukey. La concentración de cada mineral en las muestras se analizó mediante medidas repetidas a través del tiempo con el procedimiento PROC MIXED del SAS®, v. 9.1.

\section{Resultados y Discusión}

\section{Concentración de Zinc}

No se encontraron diferencias estadísticas en la concentración de $\mathrm{Zn}$ entre tratamientos (Cuadro 3) ni en la interacción tratamiento x periodo; sin embargo, existió diferencia significativa $(p<0.05)$ entre periodos de muestreo (Cuadro 4).

Arelovich et al. (2014) encontraron que dependiendo de la fuente de suplementación del $\mathrm{Zn}$ y proteína se puede modificar significativamente $(p<0.05)$ su concentración en el rumen, con valores que pueden variar desde 0.52 a $1.90 \mathrm{ppm}$.

En la Figura 1 se muestra el comportamiento de las concentraciones de los niveles séricos de Zn. Los animales de cada tratamiento mostraron niveles aceptables de $\mathrm{Zn}$ cinco días previos a la suplementación, con una variación de 1.459 a 1.497 ppm. La concentración tuvo una tendencia creciente, con excepción del día 60 , donde se apreció una disminución en todos los tratamientos, sin que existiera una explicación lógica, dado que para el siguiente muestreo (día 90) volvieron a incrementarse los niveles de $\mathrm{Zn}$.

La concentración de los niveles de $\mathrm{Zn}$ en suero sanguíneo en ovejas oscila en un rango de 0.9 a $2.0 \mathrm{mg} \mathrm{L}^{-1}$ (Underwood y Suttle, 2003). La concentración promedio de $\mathrm{Zn}$ en la presente investigación fue de 1.56 $\mathrm{ppm}$, sin diferencia estadística entre tratamientos, y se mantuvieron dentro del rango aceptado (Valle et al., 1997). Cabe señalar que los niveles de $\mathrm{Zn}$ pudieran deberse al adecuado contenido de nutrientes de la dieta basal, debido a que las reservas de este mineral son escasas (Millar et al., 1986).

Un factor a tener en cuenta en la medición de $\mathrm{Zn}$ en ovejas es la edad, debido a que animales jóvenes presentan concentraciones superiores de $\mathrm{Zn}$. En estudios realizados por Domínguez-Vara y Huerta-Bravo (2008) y 
Cuadro 3. Medias de concentración de zinc, hierro y cobre en suero sanguíneo de ovejas de pelo tratadas con diferentes niveles de suplementación

\begin{tabular}{|c|c|c|c|c|}
\hline \multirow{2}{*}{ Tratamiento } & \multirow{2}{*}{$\begin{array}{l}\text { Muestras }{ }^{1} \\
\text { (n) }\end{array}$} & Zinc & Hierro & Cobre \\
\hline & & Media (ppm) & Media (ppm) & Media (ppm) \\
\hline Compol ${ }^{\circledR}$ & 84 & 1.538 & 3.045 & 0.569 \\
\hline Fosel ${ }^{\circledR}$ & 70 & 1.522 & 3.095 & 0.521 \\
\hline Vifato ${ }^{\circledR}$ & 63 & 1.515 & 3.052 & 0.503 \\
\hline Zimacal ${ }^{\circledR}$ & 77 & 1.605 & 3.143 & 0.524 \\
\hline Media & & 1.560 & 3.078 & 0.529 \\
\hline
\end{tabular}

Cuadro 4. Análisis de varianza para las concentraciones de zinc $(\mathrm{Zn})$, hierro $(\mathrm{Fe})$ y cobre $(\mathrm{Cu})$ en suero sanguíneo de ovejas de pelo tratadas con diferentes niveles de suplementación parenteral

\begin{tabular}{lcccc}
\hline $\begin{array}{c}\text { Fuente de } \\
\text { Variación }\end{array}$ & $\begin{array}{c}\text { Grados de } \\
\text { libertad }\end{array}$ & $\begin{array}{c}\text { Cuadrado } \\
\text { medio } \\
\mathrm{Zn}\end{array}$ & $\begin{array}{c}\text { Cuadrado } \\
\text { medio } \\
\mathrm{Fe}\end{array}$ & $\begin{array}{c}\text { Cuadrado } \\
\text { medio } \\
\mathrm{Cu}\end{array}$ \\
\hline Tratamiento (T) & 3 & 0.126 & 0.158 & 0.081 \\
Repetición (R) & 38 & 0.063 & 0.284 & 0.062 \\
Muestreo (M) & 6 & $0.224^{* *}$ & $5.113^{* *}$ & $1.210^{* *}$ \\
T x M & 18 & 0.033 & 0.214 & 0.505 \\
Error & 228 & 0.059 & 0.340 & 0.078 \\
Total & 293 & & & \\
\hline
\end{tabular}

** $\mathrm{Pr}>\mathrm{F}$

Vieyra-Alberto et al. (2013) se menciona que la interacción unidad de producción, época y edad influyeron en la concentración de Zn.

Se dice que los niveles de $\mathrm{Zn}$ en animales gestantes o al inicio de la lactancia podrían presentar una disminución en su concentración debido a que el feto aumenta sus requerimientos hasta siete veces más de lo normal, como se observa en el muestreo a los 60 días posteriores a la aplicación de los tratamientos (Miller et al., 1993). Por su parte, Rosas (1999) reportó resultados contra- rios al del presente experimento, encontrando diferencias entre grupos, y donde animales en lactancia mostraron los mayores niveles de Zn. Resultados inferiores fueron obtenidos por Jia et al. (2008) en cabras suplementadas con $\mathrm{Zn}$, con concentraciones marginales de $0.84 \mathrm{ppm}$.

\section{Concentración de Cobre}

La concentración de $\mathrm{Cu}$ en plasma no fue afectada por los tratamientos ni por la interacción tratamiento x periodo; sin embar- 


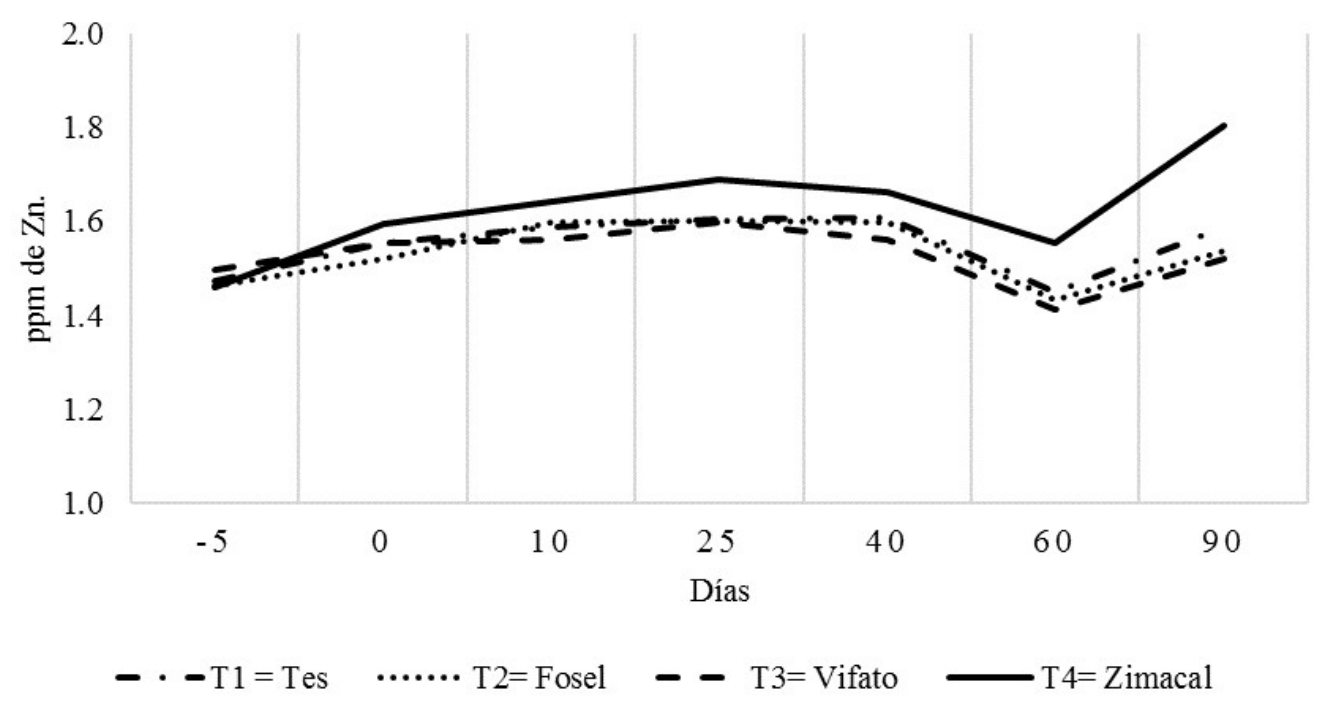

Figura 1. Concentración promedio de zinc por tratamiento en suero sanguíneo de ovejas suplementadas con minerales inyectables

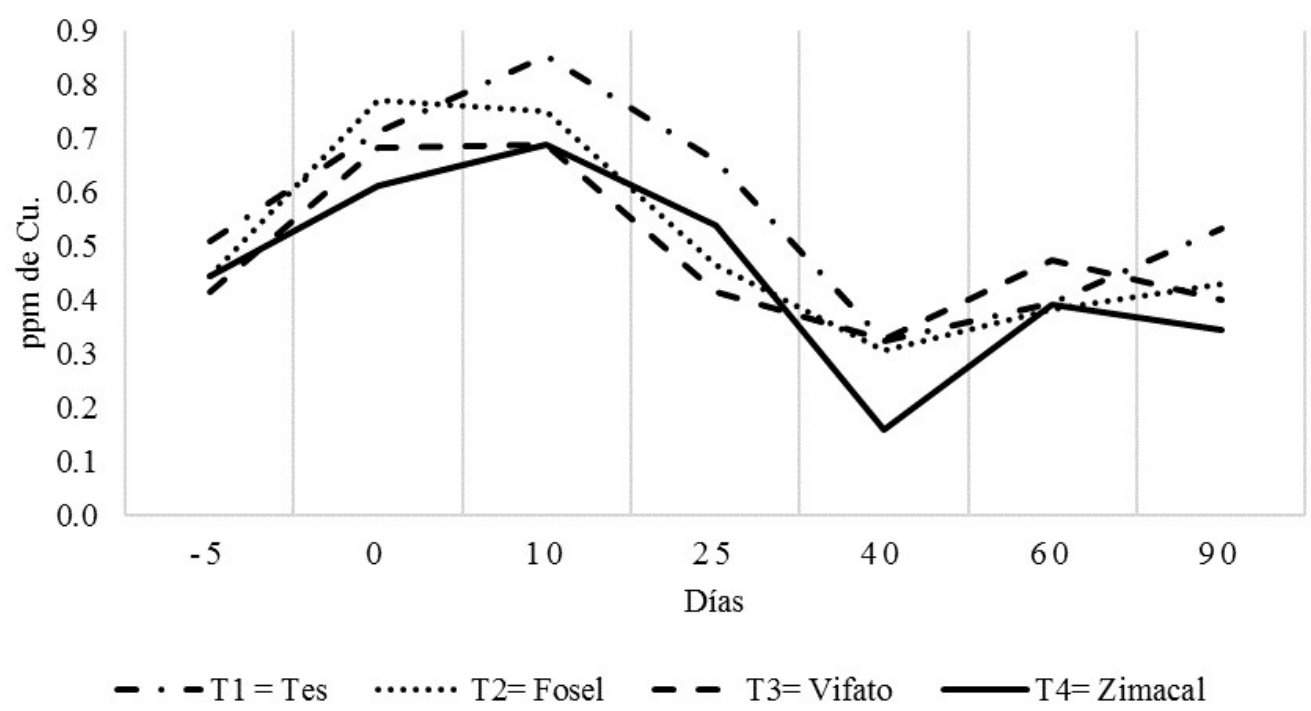

Figura 2. Concentración promedio de cobre por tratamiento en suero sanguíneo de ovejas suplementadas con minerales inyectables

go, existió diferencia significativa $(\mathrm{p}<0.05)$ entre los periodos de muestreo (Cuadro 4).

La media de concentración de $\mathrm{Cu}$ en el plasma de borregas de pelo fue de 0.529 ppm (Cuadro 2). Resultados simi- lares fueron citados por Domínguez-Vara y Huerta-Bravo (2008) y por Torres (2013) en corderos, con valores de 0.53 y $0.56 \mathrm{mg} \mathrm{L}^{-1}$, respectivamente. Sin embargo, estos valores corresponden a concentraciones marginales de acuerdo a las recomendaciones de la literatura (Valle et al., 1997; García et al., 2005). 


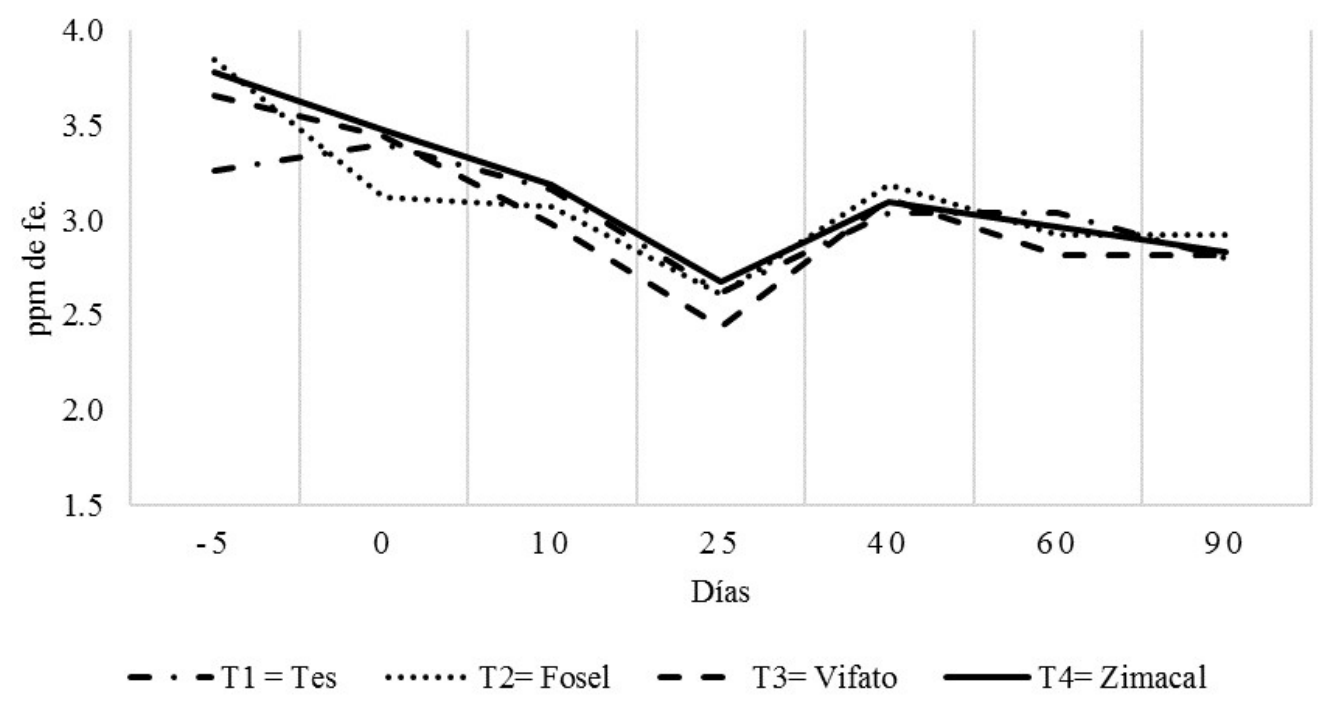

Figura 3. Concentración promedio de hierro por tratamiento en suero sanguíneo de ovejas suplementadas con minerales inyectables

Como se observa en la Figura 2, las concentraciones de $\mathrm{Cu}$ en los animales en el día -5 correspondieron a niveles marginales ( 0.415 a 0.509 ppm) en suero sanguíneo. Esta baja concentración de $\mathrm{Cu}$ es catalogada por Mills (1987) como deficiente. Durante los días 0,10 y 25 se observó un incremento en los niveles de $\mathrm{Cu}$, aunque por debajo del nivel considerado como óptimo para el $\mathrm{Cu}$ (Wittwer y Bohmwald, 1986). Asimismo, contrario a lo observado en $\mathrm{Zn}$, el $\mathrm{Cu}$ decreció marcadamente el día 40 de muestreo.

Los niveles deficientes de Cu observados en el presente estudio probablemente se deben a los niveles óptimos de $\mathrm{Zn}$, ya que este mineral es un antagonista del $\mathrm{Cu}$ (Bremner y Marshal, 1974). Asimismo, los niveles deficientes de $\mathrm{Cu}$ sérico pudieron ser el resultado de compuestos antagonistas del $\mathrm{Cu}$ presentes en el forraje como el azufre (Bremner et al., 1987), lo cual ocasiona efectos negativos ya que los suplementos minerales no pueden verse reflejados como incrementos de niveles séricos de minerales (Ward y Spears, 1993).

\section{Concentración de Hierro}

En forma similar a las concentraciones de $\mathrm{Zn}$ y $\mathrm{Cu}$, las concentraciones de $\mathrm{Fe}$ en suero sanguíneo de borregas no se vieron afectadas por los tratamientos ni por la interacción tratamiento x periodo de muestreo; sin embargo, hubo diferencias significativas $(p<0.05)$ entre los periodos de muestreo.

La media de concentración de Fe en sangre fue de $3.078 \mathrm{ppm}$, resultado similar al mencionado por Valle et al. (1997). El nivel sérico antes del inicio de la aplicación de los tratamientos (día -5) fue elevado, pero se observó una disminución persistente durante el estudio en los niveles séricos de $\mathrm{Fe}$, a pesar de los tratamientos efectuados (Figura 3 ).

Los niveles de Fe encontrados en este estudio fueron elevados, debido a que el rango considerado normal oscila de 1.3 a $2.5 \mathrm{ppm}$ (Huerta, 2008). Estos resultados podrían explicarse por el efecto que ejerció la alimentación de los animales en este estudio durante los primeros 50 días, debido a que la dieta fue 
elaborada a base de cáscara fresca de naranja. Esto pudo repercutir en una mejor absorción de Fe, tal es el caso de la vitamina A, $\mathrm{C}$ y azúcares, que al final forman elementos quelatos de $\mathrm{Fe}$, que son de fácil absorción en el intestino (Lynch y Stoltzfus, 2003).

Los niveles de Fe pueden explicar los niveles obtenidos de $\mathrm{Cu}$ debido a factores de interacción antagónica ejercida por el nivel elevado de $\mathrm{Fe}$ sobre los niveles de $\mathrm{Cu}$, pues el Fe determina la disposición del Cu. Mullis et al. (2003), en su estudio suplementando $\mathrm{Cu}, \mathrm{Zn}$ y $\mathrm{Fe}$ en vacas Angus y Simmental, observaron una disminución de $\mathrm{Cu}$ sérico y en hígado a los 140 días, cuyo efecto antagónico lo atribuyen al $\mathrm{Fe}$.

\section{Conclusiones}

Bajo las condiciones en que se llevó a cabo este experimento, se puede concluir que la suplementación mineral vía parenteral no influyó directamente sobre la concentración del $\mathrm{Zn} \mathrm{Cu}$ y Fe en suero sanguíneo.

\section{Literatura Citada}

1. Alvarez-Rodríguez J, Estopañan G, Sanz A, Dervishi E, Tamanini C, Joy M. 2012. Carry-over effects of body condition in the early pregnant ewe on peri-partum adipose tissue metabolism. J Anim Physiol Anim Nutr 96: 985-992. doi: 10.1111/j.1439-0396.2011.01210.x

2. Arelovich HM, Amela MI, Martínez MF, Bravo RD, Torrea MB. 2014. Influence of different sources of zinc and protein supplementation on digestion and rumen fermentation parameters in sheep consuming low-quality hay. Small Ruminant Res 121: 175-182. doi: 10.1016/j.smallrumres.2014.08.005

3. Bremner I, Humphries WR, Phillippo M, Walker MJ, Morrice PC. 1987. Iron-induced copper deficiency in calves: dose-response relationship and inter- action with molybdenum and sulfur. Anim Prod 45: 403-414. doi: 10.1017/ S0003356100002890

4. Bremner I, Marshall RB. 1974. Hepatic copper- and zinc-binding proteins in ruminants. 2. Relationship between $\mathrm{Cu}$ and $\mathrm{Zn}$ concentrations and the occurrence of metallothionein-like fraction. Brit J Nutr 32: 293-299. doi: 10.1079/BJN19740082

5. [CNA] Comisión Nacional del Agua. 2014. Servicio Meteorológico Nacional. Normales Climatológicas Estación San José de la Flores, Tam. [Internet]. Disponible en: http://smn.cna.gob.mx/ climatologia/Normales $8110 /$ NORMAL28197.TXT

6. Church DC, Pond WG, Pond KR. 2007. Fundamentos de nutrición y alimentación de animales. México: Ed Limusa. $635 \mathrm{p}$.

7. Domínguez-Vara IA, Huerta-Bravo M. 2008. Concentración e interrelación mineral en suelo, forraje y suero de ovinos durante dos épocas en el Valle de Toluca, México. Agrociencia 42: 173-183.

8. Fraker PJ, King LE, Laako T, Vollmer TL. 2000. The dynamic link between the integrity of the immune system and zinc status. J Nutr 130: 1399S-1406S.

9. García JD, Cuesta MM, Pedroso SR. 2005. Administración de sulfato de cobre sobre la hemoquímica, hematología y bioactividad del líquido ruminal en vacas. Rev MVZ Córdoba 10: 639-647.

10. Huerta BM. 2008. Los macro y micro minerales en la nutrición de ovinos en trópico. La Revista del Borrego 82. [Internet]. Disponible en: http:// borrego.mx/descargas/minerales.pdf

11. Jia W, Jia Z, Zhang W, Wang R, Zhang $S, Z h u X$. 2008. Effects of dietary zinc on performance, nutrient digestibility and plasma zinc status in Cashmere goats. Small Ruminant Res 80: 68-72. doi: 10.1016/j.smallrumres. 2008.09.009

12. Lynch SR, Stoltzfus RJ. 2003. Iron and ascorbic acid: proposed fortification levels and recommended iron compounds. J Nutr 133: 2978S-2984S. 
13. McDowell LR. 2003. Minerals in animal and human nutrition. $2^{\text {nd }}$ ed. Amsterdam, The Netherlands: Elsevier Science. 644 p.

14. Millar KR, Albyt AT, Meads WJ, Sheppard AD. 1986. Changes in blood levels of zinc, copper, selenium, glutathione peroxidase, vitamin B12 and total and free thyroxine in sheep removed from pasture and held without food for 50 hours. N Z Vet J 34: 1-3.

15. Miller JK, Ramsey N, Madsen S. 1993. Elementos vestigiales. En: Church DC (ed). El rumiante: fisiología digestiva y nutrición. España: Acribia. p 438-446.

16. Mills CF. 1987. Biochemical and physiological indicators of mineral status in animals: copper, cobalt and zinc. $\mathrm{J}$ Anim Sci 65: 1702-1711. doi: 10.2134/ jas1987.6561702x

17. Morales AE, Domínguez VI, González-Ronquillo M, Jaramillo EG, Castelán OO, Pescador SN, Huerta BM. 2007. Diagnóstico mineral en forraje y suero sanguíneo de bovinos lecheros en dos épocas en el valle central de México. Téc Pecu Méx 45: 329-344.

18. Mullis LA, Spears JW, McCraw RL. 2003. Effects of breed (Angus vs Simmental) and copper and zinc source on mineral status of steers fed high dietary iron. J Anim Sci 81: 318-322. doi: /2003.811318x

19. [NRC] National Research Council. 2007. Nutrient requirements of small ruminants: sheep, goats, cervids, and new world camelids. Washington DC, USA: National Academy Press. 362 p.

20. Rosas VA. 1999. Diagnóstico del estado mineral en una explotación ovina en San Juan Teotihuacán, México. Tesis de
Licenciatura. Chapingo, México: Univ Autónoma Chapingo. $60 \mathrm{p}$.

21. Torres LME. 2013. Diagnóstico mineral de unidades de producción ovina en Tepatitlán, Jalisco. Tesis de Maestría. Chapingo, México: Univ Autónoma Chapingo. $48 \mathrm{p}$.

22. Turriza-Chan JL, Castellanos-Ruelas AF, Rosado-Rubio JL, Heredia M, Cabrera-Torres E. 2010. Diagnóstico de la concentración mineral en tejido óseo de ovinos en pastoreo en el estado de Yucatán, México. Agrociencia 44: 471-480.

23. Underwood EJ, Suttle NF. 2003. Los minerales en la nutrición del ganado $3^{\circ}$ ed. Zaragoza, España: Acribia. 637 p.

24. Valle A, Quintana H, González de Pérez A, González J. 1997. Herencia de concentraciones minerales en suero sanguíneo de ovinos. Rev Fac Agron (LUZ) 14: 449-456.

25. Vieyra-Alberto $R$, Domínguez-Vara IA, Olmos-Oropeza G, MartínezMontoya JF, Borquez-Gastelum JL, Palacio-Núñez J, et al. 2013. Perfil e interrelación mineral en agua, forraje y suero sanguíneo de bovinos durante dos épocas en la Huasteca Potosina, México. Agrociencia 47: 121-133.

26. Ward JD, Spears JW. 1993. Comparison of copper lysine and copper sulfate as copper sources for ruminants using in vitro methods. J Dairy Sci 76: 2994-2998.

27. Wittwer MF, Bohmwald H. 1986. Manual de patología clínica veterinaria. Valdivia, Chile: Instituto de Ciencias Clínicas Veterinarias, Facultad de Ciencias Veterinarias, Universidad Austral de Chile. 99 p. 